\title{
Role of the gonadal vessels on the stone lodgment in the proximal ureter: Direct observation during laparoscopic ureterolithotomy
}

\author{
Mohammad Hadi Radfar ${ }^{1}$, Reza Valipour ${ }^{2}$, Behzad Narouie ${ }^{3}$, Mehdi Sotoudeh ${ }^{1}$, Hamid Pakmanesh ${ }^{4}$ \\ ${ }^{1}$ Department of Urology, Shahid Labbafinejad Medical Center, Shahid Beheshti University of Medical Sciences, Tehran, Iran; \\ ${ }^{2}$ Department of Urology, Tehran Medical Sciences Branch, Islamic Azad University, Tehran, Iran; \\ ${ }^{3}$ Department of Urology, Zahedan University of Medical Sciences, Zahedan, Iran; \\ ${ }^{4}$ Department of Urology, Shahid Bahonar Hospital, Kerman University of Medical Sciences (KMU), Kerman, Iran.
}

\begin{abstract}
Summary Introduction: Previous radiological studies revealed that stones lodge more frequently in the ureterovesical junction (UVJ) as well as the proximal ureter. Factors that prevent stone passage from the proximal ureter are not well studied. Aim: To explore the site of the lodged stones in the proximal ureter with direct observation during laparoscopic ureterolithotomy.

Materials and methods: Between November 2014 and February 2015, we included 26 patients including 18 men and 8 women with stones larger than 10 millimeters in the proximal ureter who were candidate for laparoscopic ureterolithotomy. We prospectively recorded the site of the lodged stones in the ureter during laparoscopic ureterolithotomy in relation with the sites of ureteral stenosis as well as the gonadal vessels.

Results: Among 26 patients with ureteral stone, in 19 cases stone was found close to the gonadal vein compared with seven cases that stone was in other locations of the ureter $(p=0.02)$. The characteristics of patients and stones were not different in cases that the stone was close to gonadal vessels compared with other locations.

Conclusions: This study showed that most of the stones lodged in the proximal ureter were in close proximity with gonadal vessels. Gonadal vessels may be an extrinsic cause of ureteral narrowing.
\end{abstract}

KEY WORDS: Ureter; Urolithiasis; Laparoscopy; Pathophysiology; Gonadal vessels.

Submitted 11 December 2017; Accepted 12 January 2018

\section{INTRODUCTION}

Ureteral stone is a common presentation of the urinary tract stone disease that usually is associated with an excruciating pain (1). Most of urinary tract stones pass spontaneously; however, some stones lodge in the ureter and require intervention $(2,3)$. Anecdotally, three constrictions in the ureter are told to be the potential site of stone impaction including ureteropelvic junction (UPJ), the crossing of the ureter over iliac vessels and the ureterovesical junction (UVJ) (4). In contrast with this theory, data of clinical studies did not show increased rate of stone lodgment at the level of the iliac vessels (5-7). In addition, UPJ is not a frequent location for lodged stones. Actually, studies that reviewed imaging of the patients with impacted ureteral calculus revealed that stones lodge more frequently in two sites: UVJ and proximal ureter. UVJ is known unanimously as the narrowest part of the ureter (8); however, we have not a clear response to the question that why large stones that pass the UPJ, lodge in the proximal ureter.

Ureteroscopy (TUL) or Shock wave lithotripsy (SWL) or are the first line treatment for more ureteral stones (9).

For large stone burden or when previous options have failed, laparoscopic ureterolithotomy is a less invasive technique with excellent success rate (10). In this study, we prospectively investigated the location of the lodged stones in the proximal ureter under direct laparoscopic vision in patients who were candidate for laparoscopic ureterolithotomy. To the best of our knowledge, this is the first study that report intraoperative data of lodged ureteral stones in relation with the gonadal vessels.

\section{MATERIALS AND METHOdS}

We prospectively evaluated patients who undergo laparoscopic transperitoneal ureterolithotomy for upper ureteral stones. Between November 2014 and February 2015, we included 26 patients. The inclusion criteria was stones larger than 10 millimeters in the proximal ureter (from ureteropelvic junction to the iliac vessels) in the nonenhanced spiral abdominopelvic computed tomography scan (CT-Scan), that failed to response with Shock Wave lithotripsy (SWL). We excluded patients who had previously underwent open stone surgery. A negative urine culture and normal coagulation tests was attained. The studied variables were patient demographic data including age, gender, height, weight, body mass index as well as stone characteristics including size, number and laterality and data of previous interventions. Urology and Nephrology Research Center Board of ethical approval approved the study. All procedures were in accordance with the ethical standards of the institutional and/or national research committee and with the 1964 Helsinki declaration and its later amendments or comparable ethical standards.

\section{Surgical technique}

After induction of the general anesthesia, we inserted a 
Foley catheter and orogastric tube. Then, we placed the patients in flank position and flexed the operating table at umbilical level. One surgeon, trainee fellowship of laparoscopy, under supervision of one attending staff performed all operations. We inserted a 10-millimeter trocar in the umbilicus or lateral to the rectus muscle at the umbilicus level. After insufflation, we inserted two or three working ports in a rhomboid style. The ipsilateral colon was mobilized. Then, we explored the ureter based on preoperative imaging to find the stone. Then, we evaluated the location of the stone in relation with the gonadal vessels. (Figure 1) Then, we extracted the stone through a longitudinal ureteral incision. We placed a double-J stent in all cases and repaired the ureteral incision with separate absorbable 4-0 Vicryle sutures.

\section{Figure 1.}

The location of the lodged stone in the proximal ureter in relation with the right gonadal vessels.

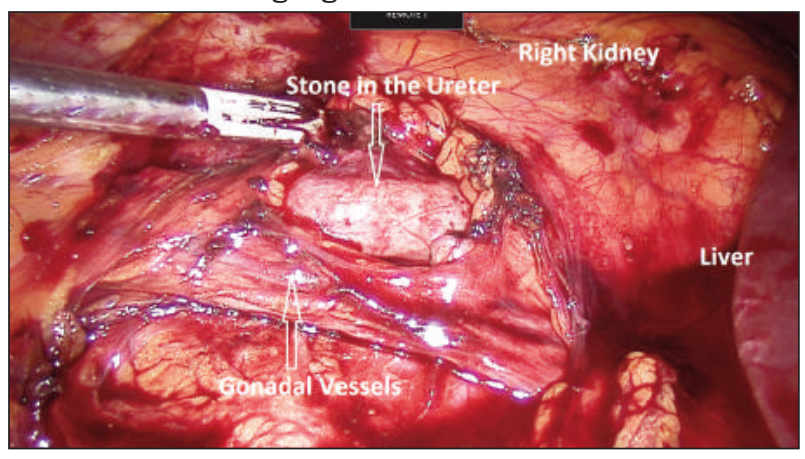

\section{Statistical analysis}

Data are presented as mean \pm standard deviation, range, numbers and percentages.

We analyzed data using nonparametric binominal test with the test proportion of 0.50 to evaluate whether the ureteral stones are randomly distributed in the ureter or not. $\mathrm{P}$ value less than 0.05 was considered significant.

\section{RESULTS}

We evaluated 26 patients including 18 men and 8 women with mean age of $48 \pm 14$ years ( 25 to 75 ).

\section{Table 1.}

Demographic and stone characteristics of patients considering the relation of the lodged stone with gonadal vessels.

\begin{tabular}{|c|c|c|c|c|}
\hline & & \multicolumn{3}{|c|}{ Location of stone } \\
\hline & & $\begin{array}{l}\text { Close to gonadal } \\
\text { vessels }(n=19)\end{array}$ & $\begin{array}{l}\text { Other locations } \\
(\mathrm{Nn}=7)\end{array}$ & $P$ value \\
\hline Laterality & $\begin{array}{l}\text { right } \\
\text { left }\end{array}$ & $\begin{array}{c}12(63.2) \\
7(36.8)\end{array}$ & $\begin{array}{l}4(57.1) \\
3(42.9)\end{array}$ & 0.78 \\
\hline Gender & $\begin{array}{c}\text { male } \\
\text { female }\end{array}$ & $\begin{array}{c}13(68.4) \\
6(31.6)\end{array}$ & $\begin{array}{l}5(71.4) \\
2(28.6)\end{array}$ & 0.88 \\
\hline Stone size & $(\mathrm{mm})$ & $16.3 \pm 6.1$ & $15 \pm 2.9$ & 0.59 \\
\hline Age (years & & $47.8 \pm 13.8$ & $50 \pm 14.1$ & 0.74 \\
\hline Height (cn & & $167.7 \pm 7.2$ & $170.7 \pm 9.8$ & 0.48 \\
\hline$\overline{\mathrm{BMI}}(\mathrm{Kg} / \mathrm{n}$ & & $25.9 \pm 3.4$ & $26.7 \pm 3.5$ & 0.6 \\
\hline
\end{tabular}

Mean BMI was $26 \pm 3 \mathrm{~kg} / \mathrm{m}^{2}$ (21 to 32). Regarding previous history of intervention, two patients had previous history of percutaneous nephrolithotomy. In sixteen cases (61\%), stone was located in the right side.

Considering the location of the stone in relation with gonadal vessels, among 26 patients with ureteral stone, in 19 cases stone was found close to the gonadal vein compared with seven cases that stone was in other locations of the ureter $(p=0.02)$. The characteristics of patients and stones were not different in cases that the stone was close to gonadal vessels compared with other cases (Table 1).

\section{Discussion}

To the best of our knowledge, this is the first report that consider the gonadal vessels as a cause of stone lodgment in the proximal ureter. UPJ is told to be one of the three constrictions of the ureter; however, there is large body of evidence that shows many stones pass the UPJ but lodge in the proximal ureter $(5,3,11,7)$. Nevertheless, no one has explained an etiological factor for this finding yet. Actually, stones that lodge in the proximal ureter are less likely to pass spontaneously with Medical Expulsive Therapy (MET) compared with lower ureter stones (12). We think that, presence of gonadal vein as an extrinsic compression against ureteral peristalsis may explain these findings.

There are some examples that a vessel can compress the ureter and produce obstruction in the upper urinary tract. Ureterovascular hydronephrosis is an example of upper tract obstruction secondary to the pressure effect on the ureter by the lower pole arterial branches. This obstruction leads to hydronephrosis resembling uretero-pelvic junction obstruction especially in children $(13,14)$.

This obstruction may be successfully resolved by laparoscopic transposition of the lower pole crossing vessels (15). Likewise, thrombosis of the ovarian vein may compress the ureter, a condition known as ovarian vein syndrome $(16,17)$.

The aforementioned conditions corroborate our finding that gonadal vessels may cause extrinsic narrowing in the ureter sufficient to prevent spontaneous stone expulsion.

Ordon et al. reviewed kidney-ureter-bladder (KUB) and CT-scan of the patients referred for SWL. They found that in this group of patients most stones were lodged at the level of the lower L2 and upper L3 vertebra followed by at the level of the iliac spine. Larger stones and stones in female patients were located more proximally (6). They concluded that the stones at the level of the L2-L3 vertebra is compatible with the UPJ. They did not considered that the gonadal vessels traverse the ureter at the same level of the vertebra. Gonadal arteries arise from the abdominal aorta at the L2 vertebral level (18) and traverse laterally and cross the ureter at L3 vertebral level. Namely, stone lodgment at the L2-L3 level may be a consequence of the extrinsic pressure of the gonadal vessels rather than functional narrowing of the UPJ.

Additionally, some other studies have shown that stones usually lodge at the upper ureter rather than UPJ. Eisner et al. retrospectively reviewed CT-Scan imaging data of 94 patients referred to the emergency department and reported that upper ureter (23\%) stone was the second most frequent site of the stone lodgment after UVJ 
(60\%). In their study, stone lodged at the UPJ level in 10 percent of cases (5). Similarly, Jong Song et al. reviewed CT-Scan imaging of 95 patients with acute renal colic and found that UPJ stone was present in only $5 \%$ of patients. In contrast, $30 \%$ of stones were detected in the proximal ureter. Interestingly, only in one case in both aforementioned studies stone was detected in the level of ureter crossing iliac vessels $(5,7)$. This data confirms that UPJ itself is not the leading cause of stone lodgment, the stones lodge in the proximal ureter instead.

El-Barky et al. published result of their prospective study on ureteral stone location in cases that were candidate for intervention due to failed MET. They reported that UVJ followed by proximal ureter were the more frequent sites of stone lodgment in this cohort. Twenty two percent of the stones were at the level of the L3-L4 vertebra in the proximal ureter whereas only $10 \%$ of stones were in the UPJ level (3). Recently, Moon et al. reviewed the finding of the computed tomography scans of the patients with ureteral stone that failed to pass the ureteral calculi after two weeks of MET. This study showed that $37 \%$ of patients that failed to response with two weeks of MET had stone in the proximal ureter, $36 \%$ in the UVJ and 2\% in the UPJ. Further, stones lodged in the upper ureter were larger than the lower ureter stones and showed lower response rate to MET (11). These findings more attest our theory that some pathophysiological factor should be present that create a constriction on the proximal ureter that interfere with stone passage.

Our finding may explain this difference likewise.

In this study, for the first time we introduce the gonadal vessels as an extrinsic factor that induce stone lodgment in the proximal ureter. Previous studies evaluated imaging studies of the patients whereas this is the first report that investigate the real place of the stone lodged in the ureter by direct laparoscopic vision. In addition, results of this study may help during laparoscopy of the ureteral stone to find the stone by focusing on the site that gonadal vessels traverse the ureter. Further studies including more patients is needed to validate our findings in the present study.

\section{Conclusions}

This study showed that most of the stones lodged in the proximal ureter were in close proximity with gonadal vessels. Gonadal vessels may be a cause of extrinsic ureteral narrowing.

\section{REFERENCES}

1. Basiri A, Shakhssalim N, Khoshdel AR, et al. Drinking water composition and incidence of urinary calculus: introducing a new index. Iranian journal of kidney diseases. 2011; 5:15-20.

2. Deliveliotis C, Chrisofos M, Albanis S, et al. Management and follow-up of impacted ureteral stones. Urol Int. 2003; 70:269-272.

3. El-Barky E, Ali Y, Sahsah M, et al. Site of impaction of ureteric calculi requiring surgical intervention. Urolithiasis. 2014; 42:67-73.

4. AI D. Anatomy and surgical approach to the urogenital tract in the male. In: Campbell M (ed) Urology. WB Saunders Company, Philadelphia/London 1954, (1st edn.), p.12
5. Eisner BH, Reese A, Sheth S, Stoller ML Ureteral stone location at emergency room presentation with colic. J Urol. 2009; 182:165-168.

6. Ordon M, Schuler TD, Ghiculete D, et al. Stones lodge at three sites of anatomic narrowing in the ureter: clinical fact or fiction? J Endourol. 2013; 27:270-276.

7. Song HJ, Cho ST, Kim KK. Investigation of the location of the ureteral stone and diameter of the ureter in patients with renal colic. Korean Journal Urol. 2010; 51:198-201.

8. Abdel Razzak OM. Ureteral anatomy. In: Smith AD B, G BD, et al, eds. Smith's Textbook of Endourology., 2nd ed. Lewiston: BC Decker Inc, pp 213-216.

9. Porpiglia F, Fiori C, Poggio M, et al. Ureteroscopy: is it the best? Urologia. 2014; 81:99-107.

10. Wu T, Duan X, Chen S, et al. Ureteroscopic lithotripsy versus laparoscopic ureterolithotomy or percutaneous nephrolithotomy in the management of large proximal ureteral stones: a systematic review and meta-analysis. Urol Int 2017 doi:10.1159/000471773.

11. Moon YJ, Kim HW, Kim JB, et al. Distribution of ureteral stones and factors affecting their location and expulsion in patients with renal colic. Korean J Urol. 2015; 56:717-721.

12. Choi T, Yoo KH, Choi SK, et al. Analysis of factors affecting spontaneous expulsion of ureteral stones that may predict unfavorable outcomes during watchful waiting periods: What is the influence of diabetes mellitus on the ureter? Korean J Urol. 2015; 56:455-460.

13. Stephens FD. Ureterovascular hydronephrosis and the "aberrant" renal vessels. J Urol. 1982; 128:984-987.

14. Pesce C, Campobasso P, Costa L, et al. Ureterovascular hydronephrosis in children: is pyeloplasty always necessary? Eur Urol. 1999; 36:71-74.

15. Gundeti MS, Reynolds WS, Duffy PG, Mushtaq I. Further experience with the vascular hitch (laparoscopic transposition of lower pole crossing vessels): an alternate treatment for pediatric ureterovascular ureteropelvic junction obstruction. J Urol. 2008; 180(4 Suppl):1832-1836.

16. JC C. The right ovarian vein syndrome. Clinical urography: an Atlas end Texbook of Roentgenologic Diagnosis $2^{a}$ ed, 1964, pp.1227-1236.

17. Derrick FC Jr., Turner WR, House EE, Stresing HA. Incidence of right ovarian vein syndrome in pregnant females. Obst Gynecol. 1970; 35:37-38.

18. Ahlberg NE, Bartley O, Chidekel N. Right and left gonadal veins. An anatomical and statistical study. Acta radiologica: diagnosis. 1966; 4:593-601.

\section{Correspondence}

Mohammad Hadi Radfar, MD

Mehdi Sotoudeh, MD

Department of Urology, Shahid Labbafinejad Medical Center, Shahid Beheshti University of Medical Sciences, Tehran, Iran

Reza Valipour, MD

Department of Urology, Zahedan University of Medical Sciences,

Zahedan, Iran

Behzad Narouie, MD

Departement of Urology, Tehran Medical Sciences Branch,

Islamic Azad University, Tehran, Iran

Hamid Pakmanesh, MD (Corresponding Author)

h_pakmanesh@yahoo.com; h_pakmanesh@kmu.ac.ir

Department of Urology, Shahid Bahonar Hospital, Kerman

University of Medical Sciences (KMU), Kerman, Iran 